\title{
Three-Dimensional Printing Fashion Product Design with Emotional Durability Based on Korean Aesthetics
}

Seonju Kam

check for updates

Citation: Kam, S. Three-Dimensional Printing Fashion Product Design with Emotional Durability Based on Korean Aesthetics. Sustainability 2022, 14, 240. https://doi.org/10.3390/ su14010240

Academic Editor: Mostafa

Ghasemi Baboli

Received: 1 October 2021

Accepted: 21 December 2021

Published: 27 December 2021

Publisher's Note: MDPI stays neutral with regard to jurisdictional claims in published maps and institutional affiliations.

Copyright: (c) 2021 by the author. Licensee MDPI, Basel, Switzerland. This article is an open access article distributed under the terms and conditions of the Creative Commons Attribution (CC BY) license (https:// creativecommons.org/licenses/by/ $4.0 /)$.
Department of Clothing and Textiles, Kyung Hee University, Seoul 02447, Korea; sjkam@khu.ac.kr; Tel.: +82-70-8610-2255

\begin{abstract}
Given the potentially significant environmental impacts of fashion design, various design approaches are required to extend product lifespan. Digital design methods may play an essential role in reducing the environmental impact of products and production processes. In addition, a design approach inspired by nature, where humans have long lived, is valid for sustainable design innovation. The purpose of this study is to examine the aesthetics of Koreans, who prefer nature, and to find a sustainable fashion design approach by using it as a knowledge database. In this study, a parametric design methodology that can reflect knowledge-based data in the process of producing 3D printing sustainable fashion products, considering the emotional durability of consumers, was used. The study results are as follows. From the aesthetic point of view of Korea, sustainable design characteristics represent unique Korean folk art, resilience to nature, and simplicity that resembles nature. The properties of the form represented to "forms resembling nature", "changeable forms", "organic forms", and "minimal forms". Materials were "nature inspired textures", "rustic natural materials", and "regional materials". Colors were "the colors of nature" and "indigenous colors". The parametric controls variables used for 3D printing the fashion products were size, assembly style, and sustainable material. These control parameters were used to create designs according to the individual taste of users. In the 3D printing fashion product design process, pieces were printed in different shapes and sizes by controlling the parameters to create designs according to users' tastes and Korean aesthetics. It was determined that this process could extend the lifespan of products, and that it is possible to modify sustainable fashion products according to personal taste by adjusting numerical values and extracting visual images based on knowledge of art and culture.
\end{abstract}

Keywords: emotional durability; 3D printing fashion product design; Korean aesthetic

\section{Introduction}

Design for sustainability first started out of concern for environmental issues; it has now gone beyond moral and ideological dimensions, and has recently evolved from a general clean production method to a focus on products, and includes the social, economic, and environmental factors of production [1].

Sustainability practices aim to increase successful interdependence between human societies and ecological systems [2]. Kozlowski et al. stated that in addition to the performance in the three aspects of environmental, social, and economic sustainability, aesthetic and cultural dimensions should also be considered [3]. However, sustainable fashion products tend to be indifferent to individual taste, lifestyle, and user properties that relate to cultural environments [4,5]. For Gwilt, from a sustainable life-cycle point of view, if users' opinions and experiences were reflected in and applied to design, this could lead to a sustainable fashion development method [6].

Sumter et al. presented several sustainable design approaches, among which are the nature-inspired design and design for social innovation that this study focuses on [7]. Being inspired by and imitating nature has long been considered a valid approach to design [8], and design methods inspired by the natural environment and living culture can serve as 
sustainable design approaches. [9,10]. These design approaches include direct, indirect, and symbolic experiences of nature, use of natural materials, small ecological footprints, and design in relation of the ecology of place, culture, and history $[8,9,11,12]$. In this respect, this study conducts research on sustainable fashion products with a focus on Korean aesthetics, which is related to both sustainability and philosophy related to nature.

Oriental philosophy implies a symbiosis between nature and humans, including Taoism — which contains ideas that are consistent with nature-,Buddhism-which believes that because everything exists in relation to each other, there is no independent entityand Confucianism - which contains the idea that nature and hu-mans are one $[13,14]$. This philosophy is reflected in traditional Korean houses and lifestyles, and is handed down to future generations via sustainable design that pursues symbiosis and coexistence with nature and ecological conservation. Culture and technology are inextricably linked; thus, sustainability combined with social considerations and improved design can address environmental challenges [15]. Computer technologies that facilitate innovative social transitions enable sustainable design processes with a focus on highly efficient solutions that minimize environmental impact, as covered in previous studies [7,15]. By manufacturing products at the last stage of the computer aided process plan, 3D printing enables a sustainable approach to design. The development of digital technology as a design expression tool increases user attention on and participation in the design. Digital technology expands design tools for society. For example, improvements in sustainability are achieved by encouraging interactions between consumers and designs. In this regard, 3D printing employs additive manufacturing (AM), an innovative technology that produces zero waste [16,17].

The purpose of this study is to present a sustainable fashion design approach using the image of Korea pursuing coexistence with nature as a knowledge-based database. In order to increase the emotional durability of consumers, a parametric design methodology through knowledge-based data in the 3D printing fashion product design process was used. Fashion products modeled through this process enable the production of eco-friendly products that pursue net zero through 3D printing using eco-friendly filaments.

\section{Theoretical Background}

\subsection{Sustainability and Local Culture}

In 1996, UNESCO published the report "Our Creative Diversity", which emphasizes the relationship between culture and sustainable development. The UNESCO Intergovernmental Conference on Cultural Policies for Development was held in Stockholm in 1998. Similar to the 1996 report, the correlation between culture and sustainability was emphasized throughout this conference; in particular, the significant contribution that creativity and cultural diversity make to sustainable development [18]. Moreover, "The Universal Declaration on Cultural Diversity" note that cultural diversity is as necessary to humanity as biodiversity is to nature. Cultural diversity is the root of economic growth as well as intellectual, sentimental, ethical, and mental achievements [19]. At the 2005 UNESCO Convention, the protection, promotion, and maintenance of cultural diversity were deemed essential to present and future sustainable development [20], suggesting that sustainability extends beyond environmental, economic, and social domains to include the cultural domains. There has been increasing attention among academics on the search for elements that correspond to consumer sensibility in sustainable development [18,21-23]. This study seeks to extend the domains covered by sustainability beyond environmental, social, and economic aspects to include cultural aspects.

Korean aesthetics incorporate the aesthetics that adapt to nature [24], and designs reflecting local cultures can increase emotional durability [22]. The Korean aesthetics see nature and humans as single entity, values harmonious living, and believe deeply in sharing with future generations [14]. Korean aesthetics emphasize nature-inspired beauty without embellishment by maintaining and utilizing the shape, texture, and color of nature [25]. Korean aesthetics align with the concepts of environmental preservation of sustainability, 
coexistence through natural circulation, the developmental evolution of ecosystems, and the pursuit of coexistence between humans and nature. For fashion products, the lifespan of the product is often determined by the empathy of and relationship with the user [6]. Objects designed to reflect local culture can build empathy and meaning for users, enabling a design that considers the user's sensibility to practice sustainability by strengthening the emotional durability of the product.

\subsection{Korean Aesthetics}

\subsubsection{Unique Korean Folk Art}

Koh, a pioneer of aesthetics in Korean art history, developed a theory on the subject of aesthetics in human life [26]. Koh claimed that Korean aesthetics reject artificial and sophisticated perfectionism and that traditional Korean art favors materials obtained from nature. He specified that Korean aesthetics have properties of folk art in that they enact understanding of cultural life sensibility. Artless art, unplanned planning, lack of refinedness, unevenness, indifference, and savory taste, which Koh considers the characteristics of traditional Korean aesthetics, mostly stem from Taoist thinking [27]. Taoism argues that the beauty of nature has achievements despite there being no artificial conduct. Moreover, rather than being guided by an artificial value system, the existence of nature itself should be the model [28]. This is similar to the study by Sumter et al. [7]. Figure 1a shows the Korean lotus design roofing tile, which Kim describes as "humane" due to its softness and mildness. Koreans admire calm and peaceful natural atmospheres without artificial decoration [29]. In Korean folk art, practical and reasonable thinking are found in unification [30]. Figure 1 b shows a traditional handmade ramie Jogakbo, a traditional practical textile constructed by joining pieces of fabric leftover from making clothes from the days when materials were scarce. Similar to a modern recycling design, Jogakbo was used not only for packaging household items or for wrapping things when moving, but also for decorative and religious purposes, making it a multifunctional item. When many pieces are connected, it symbolizes longevity and has the function of emotional durability.

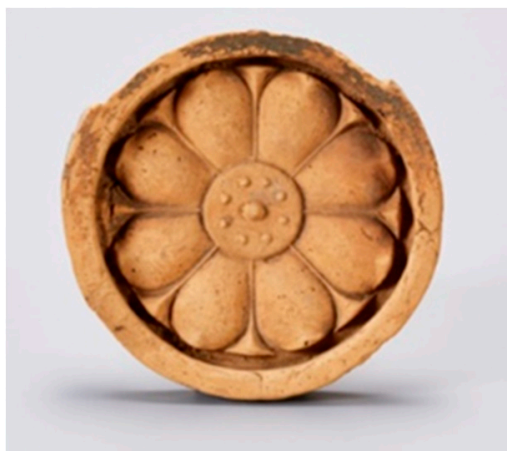

(a)

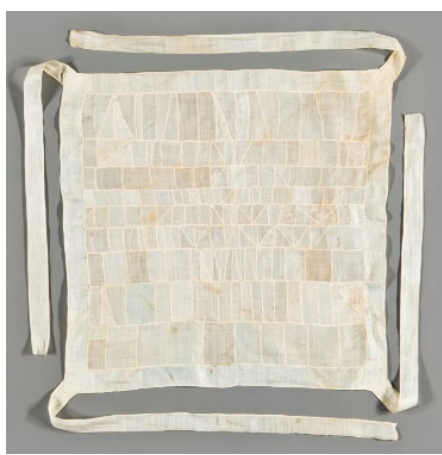

(b)

Figure 1. Lotus design roofing tile (a)—source: The National Museum of Korea (https://www. museum.go.kr/site/main/relic/search/view?relicId=116730, accessed on 21 June 2021) and Ramie Jogakbo (b)—source: The National Museum of Korea (https:/ / www.museum.go.kr/site/main/relic/ search / view?relicId=205909, accessed on 21 June 2021).

\subsubsection{Resilience to Nature}

Some properties of Korean aesthetics include valuing creativity that conveys human touch and resilience that harmonizes with nature. Resilience in Korea means that the environment and objects naturally come together, leading to an optimistic and naturalistic attitude [31]. Such attitudes align with the Buddhist concept of holism, which claims true beauty exists in the realm of no distinction between beauty and ugliness [31].

Resilience to nature uses minimal artificial lines and planes to preserve the surrounding environment and harmoniously blend with nature. Figure 2, which depicts common and 
traditional folk housing called Choga, provides an example of this. The curve of the round roof connects with the neighboring houses, in harmony with the line of the natural environment. Resilience to nature is affected by one's subconscious and holistic thought before choosing to perceive beauty or ugliness. In Buddhist thought, this is a state where the mind is immersed in one place and forgets about the self. Here, contrasting values are extolled not to be viewed dualistically but rather as a unified, monistic whole that perceives humans as part of nature [25].

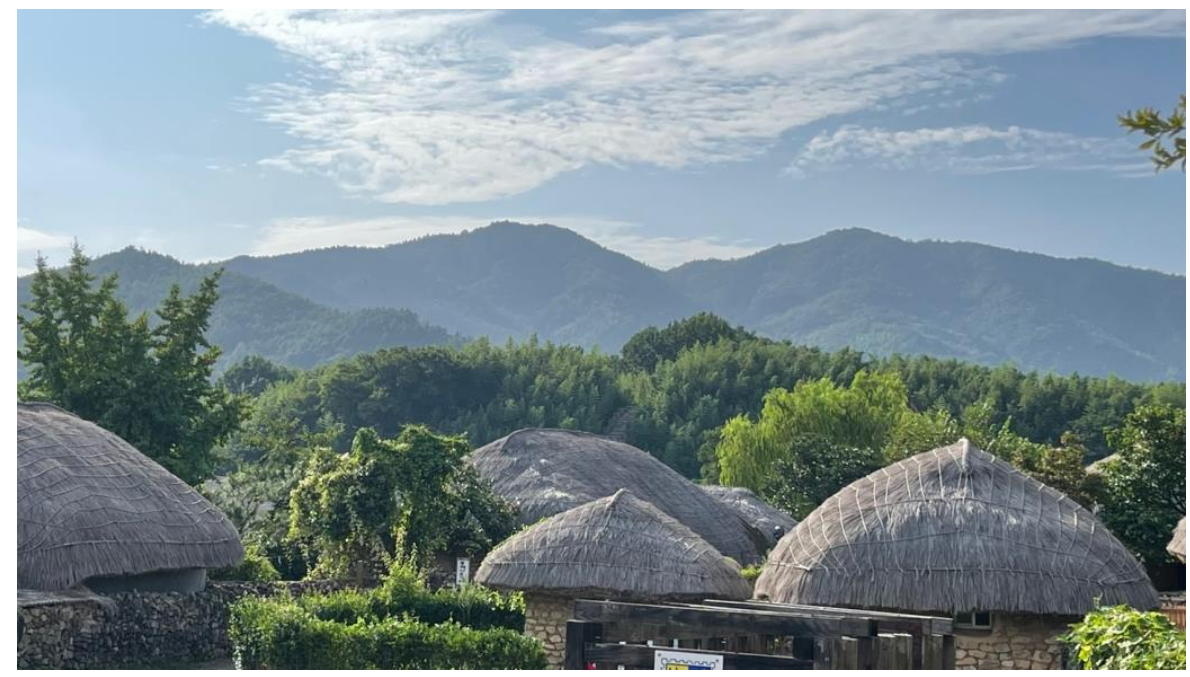

Figure 2. Korean Choga (photograph taken by the author).

\subsubsection{Simplicity Resembling Nature}

Art historian Choi emphasizes that Korean art is replete with modest, silent, elegant goodwill and noble beauty [32]. In his book "History of Korean Art", Eckardt notes that Korean art embodies simplicity above all else [33]. Eckardt recognizes the Korean aesthetics for its classic trait of having a sense of nature inspired beauty. Similarly, he recognizes its external lucidity, naturalness without exaggeration or distortion, simplicity without greed, and moderate and calmness without excess [34]. Figure 3 shows a 17-18th century jar, named the "moon jar" as it resembles the moon. The jar is simple; it is "neat", without decorations, and is a simple white color. Unnecessary elements are excluded in favor of achieving the best possible "simplicity resembling nature" [29].

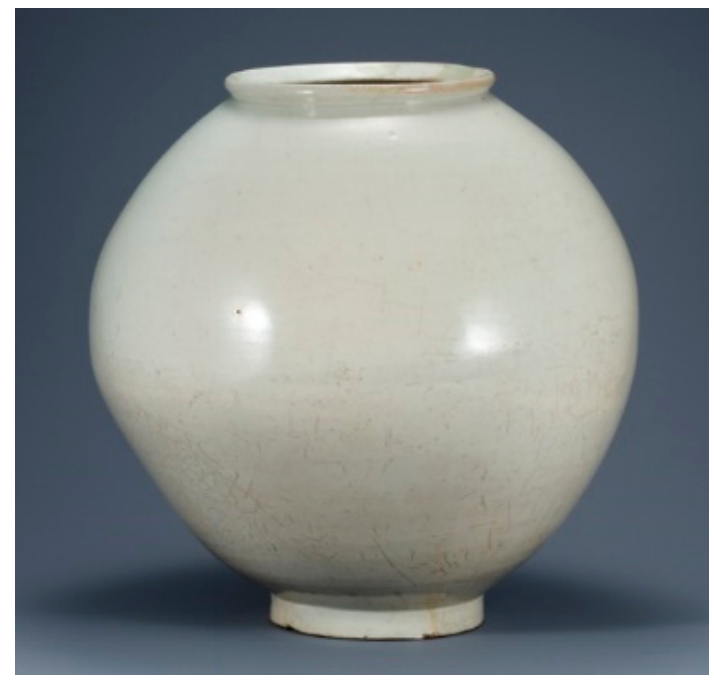

Figure 3. Moon jar. Source: The National Museum of Korea (https://www.museum.go.kr/site/ main/relic/search/view?relicId=941, accessed on 21 June 2021). 
Figure 4 shows the oriental philosophy that influences Korean aesthetics and sustainable design through Korean aesthetics. Oriental philosophy that influences Korean aesthetics, including Taoism, Buddhism, and Confucianism, is also in contact with the concept of sustainability. This can be summarized as characteristics of Korean aesthetics including unique Korean folk art, resilience to nature, and simplicity resembling nature.
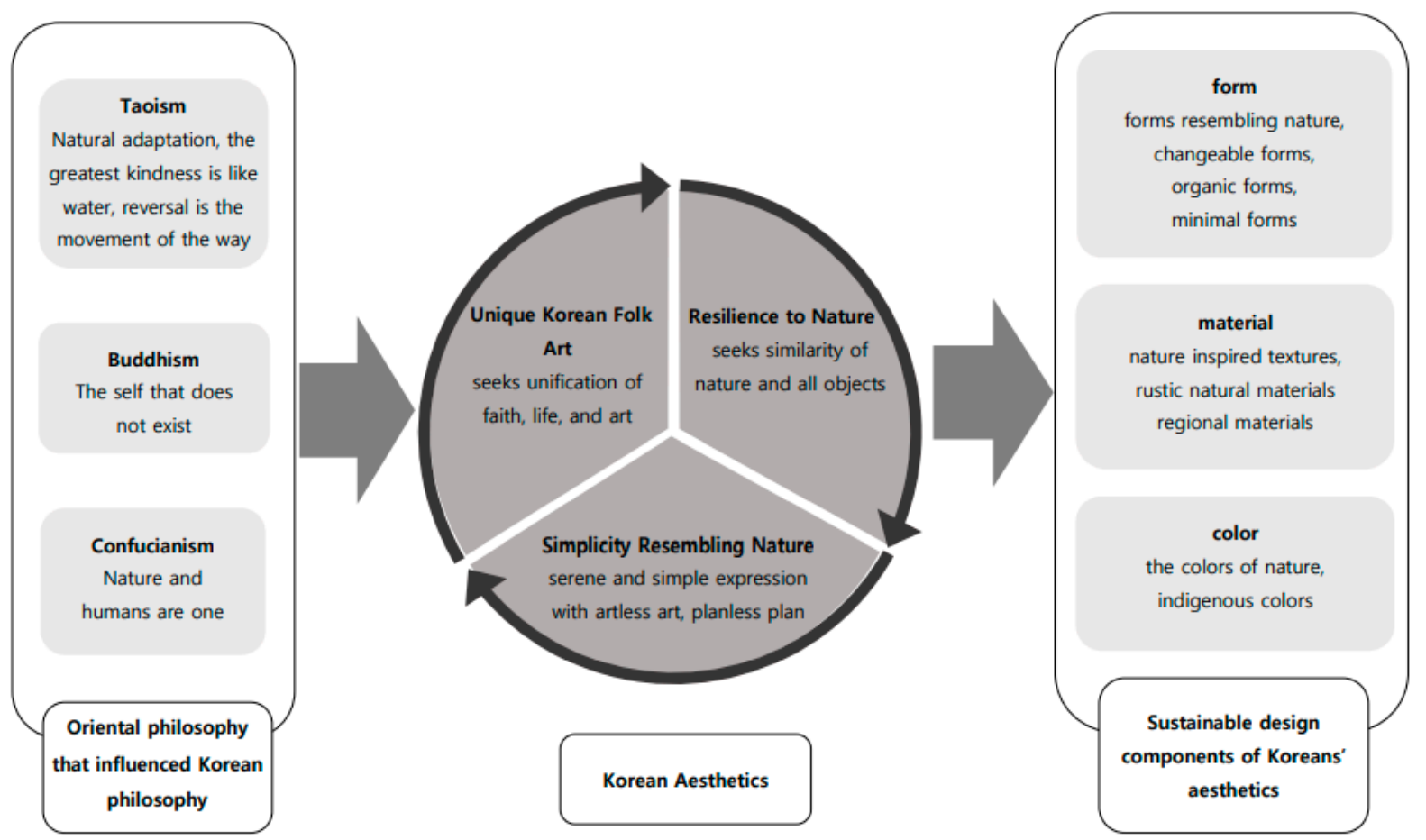

Figure 4. Oriental philosophy influencing Korean philosophy, aesthetics, and sustainable design. Source: the author.

\subsection{Parametric Design}

Parametric design is a computer expression method that creates a shape by parameterizing design properties into geometric elements. New shapes can be developed by changing parameters without erasing or redrawing the modeled design [35,36]. A parametric model is a computed design of geometric elements with fixed properties and other properties that can be changed. Variable properties are also called parametric properties, and fixed properties are called constraining properties. Designers change the parameters of a parametric model to find alternative solutions to the problems at hand [35]. In most CAD systems, procedural information about how a designer creates a design model is basically kept at the most basic level to implement functions such as do, undo, and redo, and few tools are provided for manipulating the process. Script editors and interpreters mostly operate as extensions and customizations of the system and are not properly designed for use by designers for modeling [37]. Therefore, it is necessary to present a parametric design process, which models fashion products. A parametric process is created with an algorithm that implements the designer's ideas. The generated algorithm can create and transform various instances by adjusting the original parameters such as the position, scale, and angle of the shape according to the concept, and the user can obtain an output suitable for the intention through simulation [38]. Yoo et al. said that a parametric design process based on the geometric principle of morphogenetic technique and the aesthetics obtained from nature can bring about this creative design result [39]. In this study, by using cloud technology to store modeled data, Fusion 360, which has the advantage of being easy to share with collaborators, was used as software. 


\section{Research Methods}

This study aimed to develop sustainable fashion design products based on the characteristics of Korean aesthetics, including the concept of sustainability. Modeling data for $3 \mathrm{D}$ printing product development are calculated in the parametric design process, and it is possible to develop products with emotional durability through user intervention along with knowledge-based data of Korean aesthetics. Parametric design is widely used in software modeling. It allows various design alterations without deletion or a need to redraw [35]. Parametric modeling can directly convert the numerical values set up by the designer [40]. The designer creates an algorithm suitable to the concept by extracting the concept into a visual idea based on knowledge of art culture theory. Here, a basic gene is formed in the design. This gene communicates the generation of not only the general geometric structures but also the basic, underlying patterns of the design. In this study, a parametric design method was used, in which the designer adjusts the numerical value of the product model modeled by the designer based on the knowledge base of Korean aesthetics with the concept of sustainability.

\subsection{Research Process}

The sustainable product design development process is summarized in Figure 5, which was developed by the researchers using the parametric methodology concept based on Figure 5. This process explored sustainable design in Korean aesthetics and developed it into a knowledge base, with parametric components related to product size and material established. In this study, a necklace was selected as the type of fashion product. The reason is that various design changes are possible by manipulating the various pendant shapes and assembly styles that designers create through modeling data. Designers can reflect user preferences and tastes when it comes to parametric control of pendant size and assembly style.

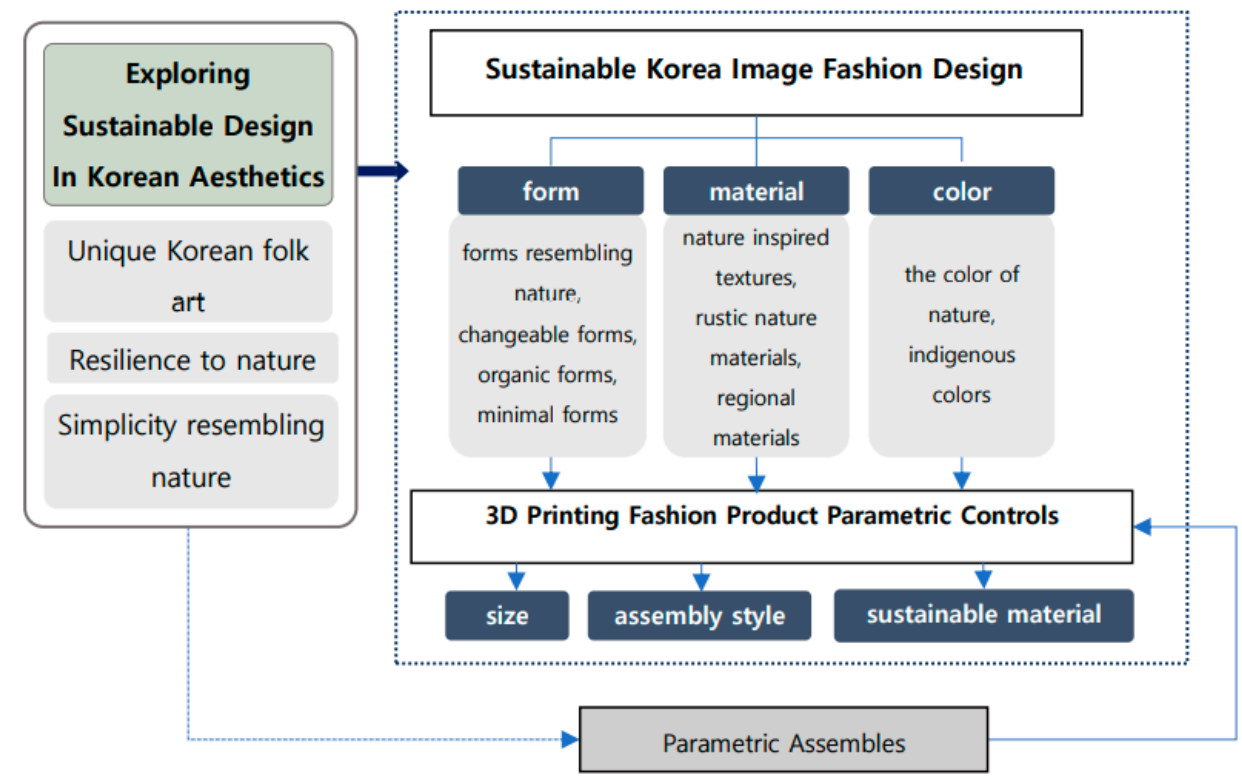

Figure 5. The 3D printing fashion product design process based on Korean aesthetics. Source: the author.

\subsection{Three-Dimensional Printing Product Design Development Tools}

In this study, the software program, printer, and sustainable filaments were considered as development tools for designing sustainable fashion products. Fusion 360: (2020 version, Autodesk, San Rafael, CA, USA) software was used, as it has the advantage of utilizing cloud technology that can store data and can be shared with collaborators to reduce time and carbon footprint [41]. The sustainable 3D printing filament used in this study is 
not a commercially available. Because it proved difficult to achieve compatibility with manufactured 3D printers, the researcher built a modular 3D printer to print the sustainable wood filament. There are many sustainable 3D printing filaments on the market, including beer filament [42], which is produced from waste by-products from the beer brewing process, recycled filament [43], based on recycled plastic, algae-based filament [44], Pāua shell filament [45], and wood filament [46]. All products printed with the wood filament are environmentally friendly in that they decompose when placed in the compost or are sent to a landfill [47]. Wood filament was selected because it had the least plastic "feel" among sustainable filaments, and the surface feeling of the print was considered to capture the simplicity of Korean aesthetics. In addition, it may stimulate the emotional durability of consumers of sustainability, who prefer a sense of "friendliness" to nature, as it exhibited less artificiality of feeling and showed the natural properties of wood.

\section{Results}

\subsection{Three-Dimensional Printing Fashion Products Design Process Based on Korean Aesthetics}

\subsubsection{Exploring Sustainable Design Based on Korean Aesthetics}

As discussed above, the sustainable fashion design characteristics discovered in Korean aesthetics were unique Korean folk art, resilience to nature, and simplicity resembling nature. The design of the case product was inspired by the lotus design in Figure 1. This pattern was extracted from roof tile design - an element of Korean architecture. The lotus pattern constitutes unique Korean folk art, and although it is not perfect, it expresses Korean beauty in that it is easy to compute with a symmetrical pattern and there are few artificial elements. This image was translated into digital data. Then, the parametric function and the limit scale were set up through the 3D software program.

\subsubsection{Parameter Control}

The components of sustainable fashion design are form, material, and color. The properties of form that reflect Korean aesthetic consciousness are "form resembling", "nature", "variable form", "organic form", and "minimal form". The material properties are "the texture of nature", "rustic nature materials", and "regional materials". The color properties are "the colors of original nature" and "indigenous colors". Based on this, size, the assembly style of the necklace, and sustainable filament were set as the moderator variable for the sustainable properties of the necklace. By limiting the associated numerical value during the fashion product modeling process, the internal design shape was configured to not invade the outline. This allows various size graftings to be initiated within the given limits, and the variables can be adjusted to reflect the user's taste in line with the program designed by the designer and can be changed into various designs.

\subsubsection{Three-Dimensional Printing Process}

Figure 6 shows the six steps involved in the 3D printing of the fashion product.

(1)

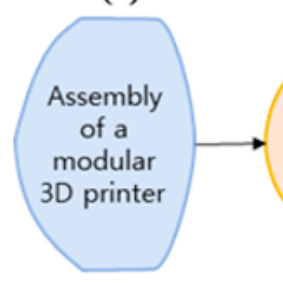

(4)

(2)

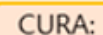

Chosen as

the slicing

software

\section{(3)}

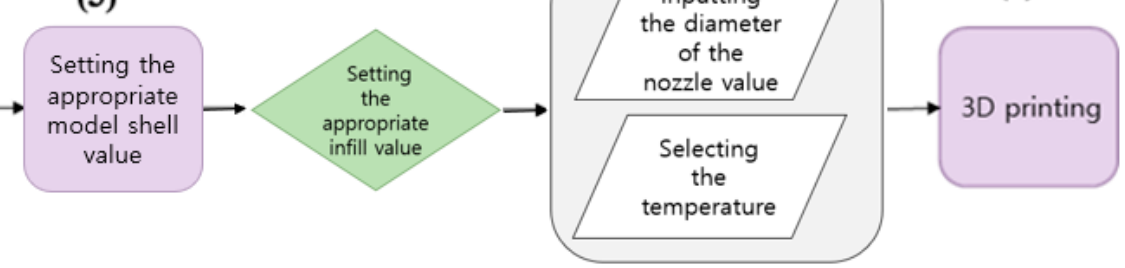

Figure 6. A concept diagram for the process of 3D printing. Source: the author.

The first step was the assembly of a modular 3D printer. Sustainable 3D printing filaments are not yet widely used, and compatibility with existing 3D printers is low. Hence, 
a modular 3D printer was developed. Exploration of a slicing program that can insert an optimal output value depending on the filament substance was required. The narrow nozzle of the manufactured 3D printer clogged when the wooden substance combined with PLA during printing, implying a need to develop a modular 3D printer using open-source 3D printer data. The nozzle of manufactured 3D printers is normally $0.4 \mathrm{~mm}$ thick. The nozzle becomes damaged when using a foreign filament, after which there is no guarantee of quality. This study used a $0.6 \mathrm{~mm}$ nozzle instead. The newly assembled printer required tuning of the output data for normal operation. In the second step, the slicing software was explored. To 3D print the final digital data, CURA: (version 15.04.6, Ultimaker, Utrecht, The Netherlands) was chosen, as it ensures that the form has strong durability even with a minimal amount of 3D data. CURA also helps the 3D printer use the proper number of filaments without waste. The third step consists of setting the appropriate model shell value for product stabilization, post-printing. In the fourth step, the appropriate infill value was set to maintain a stable form with minimal filament consumption. The fifth step involved inputting the diameter of the nozzle value and selecting a temperature suitable for the filament type. To prevent contraction caused by a temperature difference during the printing process, the bed temperature was heightened. In the sixth step, the researchers printed from the 3D printer using the sustainable filament.

In a previous study, the traditional texture was reproduced through wood, stone, soil, and more. That study utilized local and endemic materials that constitute sustainable Korean materials. In the case of wood filaments, the wooden substance is already ground down during wood processing; this shortens the filament-production process and allows for recycling. Filaments containing wood and PLA show high biodegradability and are thus eco-friendly. A major reason to use the wood filament is the outstanding aesthetic of the final products in comparison to plastic products. The wood filament in this study produced natural wood grain-like texture, and the color required no post-processing. The $3 \mathrm{D}$ printing filament printing process is shown in Figure 7.

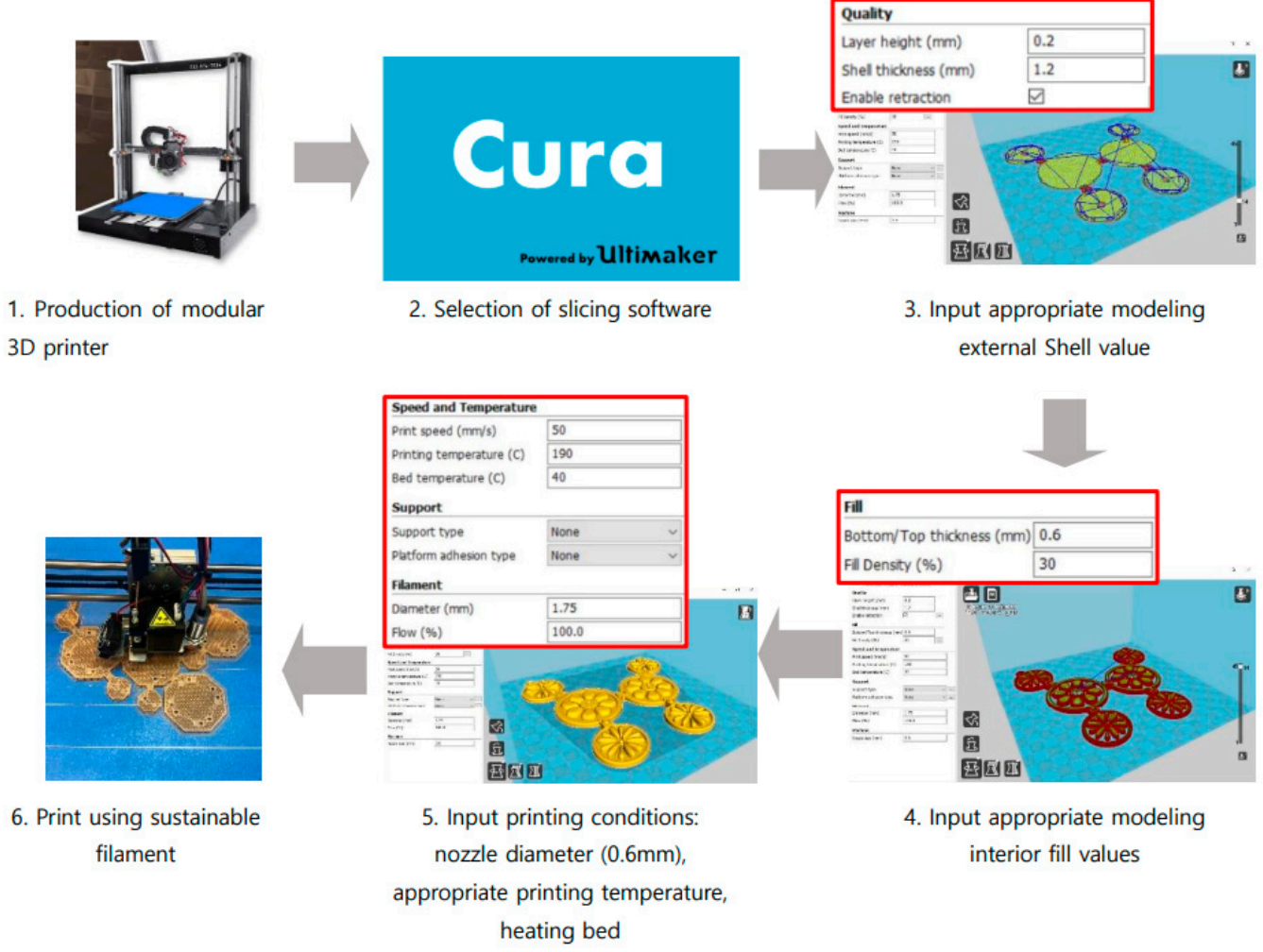

Figure 7. The 3D printing process. Source: the author. 


\subsection{Three-Dimensional Printing Necklace Based on Korean Aesthetics Development Results}

In this study, a necklace with emotional durability was developed for those who prefer the Korean philosophy of coexistence with nature and nature-inspired design. To this end, the pendant of the necklace was designed with the image of a roofing tile with a lotus flower pattern; this is easy to apply the parametric design methodology to, is based on original and unique Korean folk art, and has an assembly for which the design can be changed in line with the user's choice. In Korea, the lotus flower symbolizes Buddhism and has the meaning of always being clean, even in a dirty place [48]. This is similar to Korea's resilience to nature aesthetics, which finds beauty by adapting to nature. The lotus pattern is used not only in Korean architecture, but also in stationery, crafts, and folk crafts such as ceramics [49]. In addition, it may strengthen a user's emotional durability as it is often used as a pattern to pray for family happiness [50].

In this study, a necklace design was proposed with two roofing tile images with different lotus patterns, shown as " 1 " and " 2 " in the first column of Figure 8. Model creation was initiated by digitizing the design sketch. A total of two pendant designs were developed from these image data. The 3D print digital data design parametric components were shape and size, assembly style, and combination. The two pendant designs are shown as " 3 " and " 4 " in the shape column of the $3 \mathrm{D}$ printed digital data design parameter control in Figure 8. The parametric function was set in the digitalized model, and the limit range was set depending on the function. This setting and range limit allowed automatic adjustment of the connected flower's petal and anther size by adjusting the size of the outline. Parametric variable adjustment of the desired area can change the size of each part. I proposed 3-1, 3-2, 4-1, and 4-2 pendants in the size section by changing the dimensions of pendants 3 and 4 . In this study, only four samples were made in the size section, but more size conversions are possible according to the designer's intentions. There are two types of assembly styles for connecting pendants, suggested as " 5 " and " 6 " of the assembly column. The design can be changed according to the user's taste by suggesting different types of assemblies as modeling data. For the connecting parts, the 3D printer's assembly function was used, with Fusion 360 selected as the 3D digital software. Fashion products require an assembly process but when the assembly function is used, it can be planned in the digital data. This allows assembly simulation before printing. Therefore, it is possible to print all at once in the assembled state. The assembly function allows a sustainable production process by saving raw material use, allowing for zero waste, and reducing production time and cost. The assembly design was designed into hinge and chain style. If the assembly style connecting the pendant is designed in more styles, the diversity of designs can be increased.

In this study, six necklace designs were proposed-ND.1, ND.2, ND.3, ND.4, ND.5, and ND.6, as shown in the combination column. Depending on how the pendant and assembly style are combined, various design changes are possible. For example, ND.1 is a necklace design made using 3-1 and 3-2 pendants and assembly style 5. ND.2 was completed by combining size-adjusted 3-2 and 4-1 pendants with assembly style 6. ND.3 used size-adjusted 3-1, 3-2, and 4-1 pendants and assembly style 5. Connecting multiple pieces or reducing the number of pieces stimulates the user's emotional durability.

Figure 8 depicts the design process, showing the development process for a 3D printed necklace based on Korean aesthetics, through a parametric design methodology and process. 


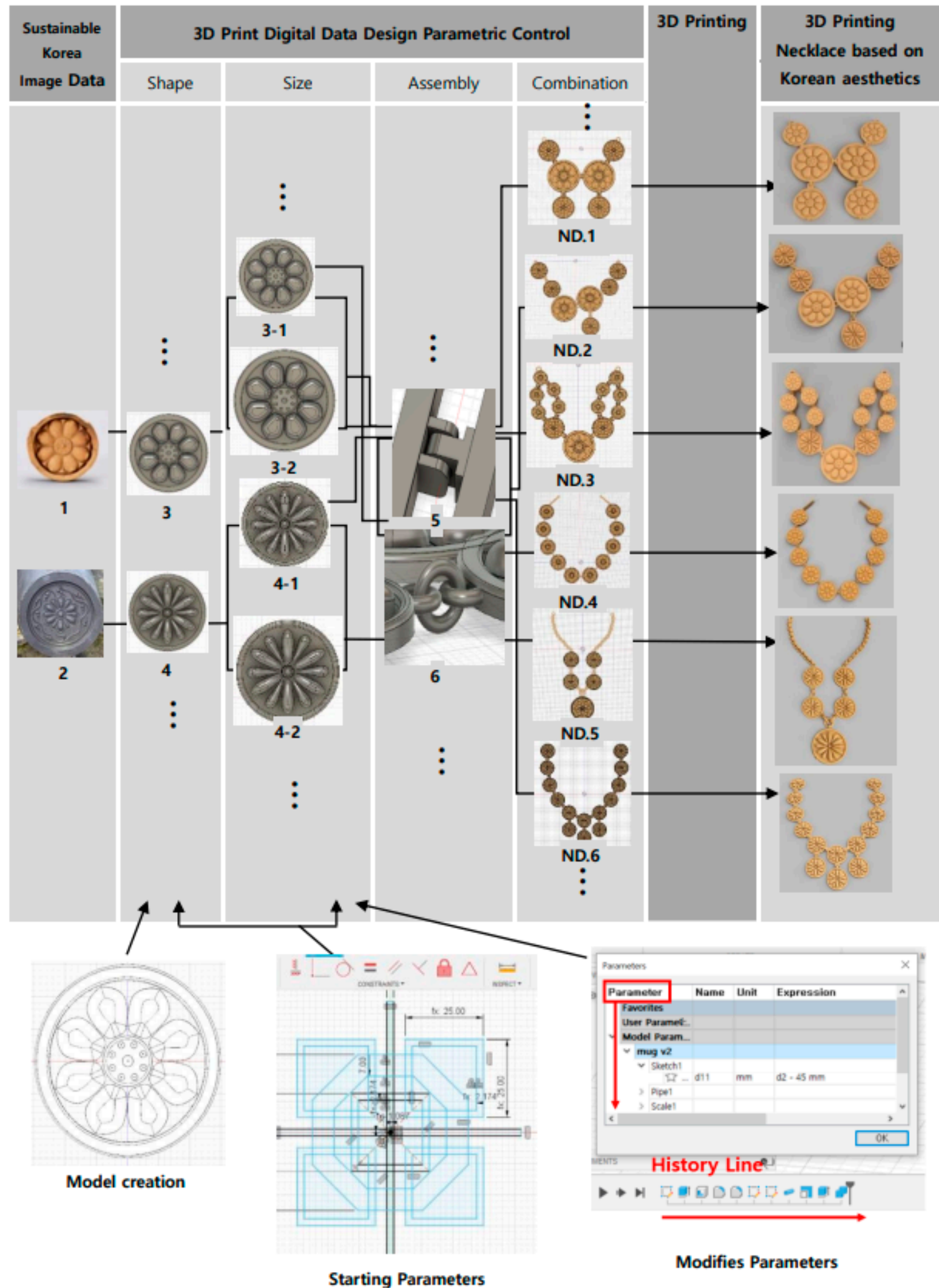

Figure 8. Three-dimensional printing of necklaces based on Korean aesthetics. Source: the author. 


\section{Conclusions}

Various attempts are being made to develop a sustainable design process that changes with the development of digital technology. While the popularity of sustainability is affecting the fashion industry, users are dissatisfied with the level of sustainable design currently available. Therefore, this study proposed an objective process by creating an algorithm that increases the emotional attachment of users by incorporating a sustainable Korean aesthetic into the design process created by the designer's intuition. To find a creative expression method for sustainable design, the direction and relevance of sustainability were explored via Korean aesthetics. With an adaptive thinking that considers nature and humans together, the Korean aesthetic sense of living in harmony with the environment exhibits many elements of current trends in sustainable development. This has had an impact on Korean life in general, and has helped to solve the problem of creative elements of Korean design.

This study is meaningful in that it formulates an objective process by conceptualizing parts that could not be objectified only by design sensibility, extracting them as visual ideas based on knowledge of art and culture theory, and creating algorithms suitable for concepts. This process allows users to participate in the production process, thereby satisfying their sensibility and taste, and hence incorporating the aesthetic and cultural dimensions of sustainability, which were previously neglected. Through this process, the user selects a preferred variable among those set by the designer, thereby increasing the degree of attachment to the selected product by increasing participation compared with existing products.

This study is also meaningful in that it extends the product life-cycle through this attachment. The results of this study, which digitized Korean images against the backdrop of Korean aesthetics with flexible adaptability while coexisting with nature, were able to develop various sizes and designs via parametric numerical control, which is expected to expand the scope of emotional durable product development by providing users with limited data. In addition, it is expected that implementing assembly functions with digital data will reduce the time and cost required for the manufacturing process and help practice sustainable fashion products in that it attempted to modularize products. However, for the results of this study to become practical, a follow-up study is needed to investigate the users of this product.

Funding: This research received no external funding.

Data Availability Statement: Data available on request due to restrictions e.g., privacy or ethical.

Conflicts of Interest: The author declares no conflict of interest.

\section{References}

1. Clark, G.; Kosoris, J.; Hong, L.N.; Crul, M.R.M. Design for sustainability: Current trends in sustainable product design development. Sustainability 2009, 1, 409-424. [CrossRef]

2. Spangenberg, J.H.; Fuad-Luke, A.; Blincoe, K. Design for Sustainability (DfS): The interface of sustainable production and consumption. J. Clean. Prod. 2010, 18, 1485-1493. [CrossRef]

3. Kozlowski, A.; Bardecki, M.; Searcy, C. Tools for Sustainable Fashion Design: An Analysis of Their Fitness for Purpose. Sustainability 2019, 11, 3581. [CrossRef]

4. Agost, M.-J.; Vergara, M. Principles of Affective Design in Consumers' Response to Sustainability Design Strategies. Sustainability 2020, 12, 10573. [CrossRef]

5. Rahman, O.; Gong, M. Sustainable practices and transformable fashion design-Chinese professional and consumer perspectives. Int. J. Fash. Des. Technol. Educ. 2016, 9, 233-247. [CrossRef]

6. Gwilt, A. Valuing the Role of the Wearer in the Creation of Sustainable Fashion. Res. J. Text. Appar. 2013, 17, 78-86. [CrossRef]

7. Sumter, D.; De Koning, J.; Bakker, C.; Balkenende, R. Circular Economy Competencies for Design. Sustainability 2020, $12,1561$. [CrossRef]

8. Ceschin, F.; Gaziulusoy, I. Evolution of design for sustainability: From product design to design for system innovations and transitions. Des. Stud. 2016, 47, 118-163. [CrossRef]

9. Dias, B.D. Beyond sustainability-biophilic and regenerative design in architecture. Eur. Sci. J. 2015, 11, 147-158. 
10. Ramzy, N. Sustainable Spaces with Psychological Values: Historical Architecture as Reference Book for Biomimetic Models with Biophilic Qualities. Archnet-IJAR Int. J. Arch. Res. 2015, 9, 248. [CrossRef]

11. Naderi, J.R.; Kellert, S.R.; Heerwagen, J.H.; Mador, M.L. Biophilic Design: The Theory, Science and Practice of Bringing Buildings to Life; John Wiley and Sons: Hoboken, NJ, USA, 2009; Volume 93, pp. 262-265.

12. Joye, Y. Cognitive and Evolutionary Speculations for Biomorphic Architecture. Leonardo 2006, 39, 145-152. [CrossRef]

13. Lee, S.J. Study on Monistic Design Thought and Method. Arch. Des. Res. 2004, 17, 479-486.

14. Yang, E.J.; Kim, K.H. The Study on Characteristics of Korean Traditional Space from an Ecological and Aesthetic Point for View. Korean Inst. Inter. Des. J. 2010, 19, 57-66.

15. Ramani, K.; Ramanujan, D.; Bernstein, W.Z.; Zhao, F.; Sutherland, J.; Handwerker, C.; Choi, J.-K.; Kim, H.; Thurston, D. Integrated Sustainable Life Cycle Design: A Review. J. Mech. Des. 2010, 132, 091004. [CrossRef]

16. Gebler, M.; Uiterkamp, A.J.S.; Visser, C. A global sustainability perspective on 3D printing technologies. Energy Policy 2014, 74, 158-167. [CrossRef]

17. Atzeni, E.; Salmi, A. Economics of additive manufacturing for end-usable metal parts. Int. J. Adv. Manuf. Technol. 2012, 62, 1147-1155. [CrossRef]

18. Soini, K.; Birkeland, I. Exploring the scientific discourse on cultural sustainability. Geoforum 2014, 51, 213-223. [CrossRef]

19. The United Nations Educational, Scientific and Cultural Organization (UNESCO). UNESCO Universal Declaration on Cultural Diversity 2 November 2001. In Standard-Setting at UNESCO; The United Nations Educational, Scientific and Cultural Organization (UNESCO): Paris, France, 2007; pp. 707-712.

20. The United Nations Educational, Scientific and Cultural Organization (UNESCO). Convention on the Protection and Promotion of the Diversity of Cultural Expressions 2005. In Proceedings of the Paper Presented at the General Conference of the United Nations Educational, Scientific and Cultural Organization, Paris, France, 3-21 October 2005.

21. Burcikova, M. One Dress: Shaping Fashion Futures through Utopian Thinking. Fash. Pr. 2019, 11, 328-345. [CrossRef]

22. Sandhu, A. Fashioning Wellbeing Through Craft: A Case Study of Aneeth Arora's Strategies for Sustainable Fashion and Decolonizing Design. Fash. Pract. 2020, 12, 172-192. [CrossRef]

23. Armstrong, C.M.; Niinimäki, K.; Lang, C. Towards Design Recipes to Curb the Clothing Carbohydrate Binge. Des. J. 2016, 19, 159-181. [CrossRef]

24. Fletcher, K. Durability, Fashion, Sustainability: The Processes and Practices of Use. Fash. Pract. 2012, 4, 221-238. [CrossRef]

25. Choi, M. A Study on the 'Win-Win' Design Direction for Nature and Human Beings with Special Reference to Oriental Ideas and Korean Aesthetic Beauty. Bull. Korean Soc. Basic Des. Art 2010, 11, 477-490.

26. Korean Association of Industrial Designers. Korean Design Application Case Study; Ministry of Trade, Industry and Energy: Gwacheon, Korea, 1997.

27. Cho, M. Philosophy: Confucianist and Taoist Aesthetic Contemplation on the Study of the Features of Korean Aesthetic Beauty. Korean Philos. Cult. 2012, 65, 299.

28. Kim, S.H.; Hur, B.P. A Study on Sustainable Earth Architecture Characteristics from an Ecological Aesthetic Point of ViewAround the Thoughts of Lao-tzu. Korean Inst. Inter. Des. J. 2011, 20, 54-62.

29. Choi, J. Korean Beauty, the Aesthetics of Freedom: Why Korean Beauty Here and Now; Hyohyung: Seoul, Korea, 2000.

30. Park, J. Chosun's Crafts and Yanagi Muneyoshi's Viewpoint of Tea-Tao. J. Tea Cult. Ind. Stud. 2006, 3, 1-13.

31. Kim, W. Exploring Korean Beauty, 6th ed.; Youlhwadang: Seoul, Korea, 1996.

32. Kwon, Y. Re-reading Korean Beauty: 100 Years Discussion on Korean Beauty Seen through 12 Aestheticians, 6th ed.; Dolbegae: Paju, Korea, 2005.

33. Eckardt, A. A History of Korean Art; Hiersemann: Leipzig, Germany, 1982.

34. Kwon, Y. Andreas Eckardt's Art History Perspectives. Korean Bull. Art Hist. 1992, 5, 5-31.

35. Hernandez, C.R.B. Thinking parametric design: Introducing parametric Gaudi. Des. Stud. 2006, 27, 309-324. [CrossRef]

36. Lotfabadi, P.; Alibaba, H.Z.; Arfaei, A. Sustainability; as a combination of parametric patterns and bionic strategies. Renew. Sustain. Energy Rev. 2016, 57, 1337-1346. [CrossRef]

37. Shih, S.-G. Notes on Generative Modeling, Procedural Symmetry, and Constructability of Architectural Design. Comput. Des. Appl. 2014, 11, 518-525. [CrossRef]

38. Abdullah, H.K.; Kamara, J.M. Parametric Design Procedures: A New Approach to Generative-Form in the Conceptual Design Phase. Archit. Eng. Conf. 2013, 201, 334-343.

39. Yoo, Y.S.; Cho, M.; Eum, J.S.; Kam, S.J. Biomorphic Clothing Sculpture Interface as an Emotional Communication Space. Front. Psychol. 2020, 11, 117. [CrossRef] [PubMed]

40. Verroust, A.; Schonek, F.; Roller, D. Rule-oriented method for parameterized computer-aided design. Comput. Des. 1992, 24, 531-540. [CrossRef]

41. Total 3D Printing. Fusion 360 vs AutoCAD [2021]: Which CAD Software Is Best? Available online: https://total3dprinting.org/ fusion-360-vs-autocad-compared/ (accessed on 21 June 2021).

42. 3D Print with Beer Filament [Internet]. 2015. Available online: https://all3dp.com/3d-print-with-beer-filament/ (accessed on 21 June 2021).

43. Pinshape. Guide to Green 3D Printing—4 Ways to Be More Sustainable! Available online: https://pinshape.com/blog/guidegreen-3d-printing/ (accessed on 21 June 2021). 
44. Global Opportunity Explorer. Algae-Based 3D-Printing Filaments. Available online: https://goexplorer.org/algae-based-3dprinting-filaments / (accessed on 21 June 2021).

45. Scion Research (YouTube). Scion Paua Power. Available online: https://youtu.be/lvxshNCNFp4 (accessed on 24 August 2021).

46. 3DINSIDER. Wood Filament: Properties, How to Use Them, and Best Brands. Available online: https://3dinsider.com/woodfilament/ (accessed on 21 June 2021).

47. 3D Printer and 3D Printing News. Jelwek Launches 3D Printed, Wood Filament Watch Collection. Available online: https:// www.3ders.org/articles/20141214-jelwek-launches-3d-printed-wood-filament-watch-collection.html (accessed on 21 June 2021).

48. Kim, J.; Yoon, P.; Kim, Y. Geometric and Design Form, Container Type, and Plant Materials of the Korean Traditional Buddhist Flower Arts. J. Korean Soc. Flor. Art Des. 2008, 18, 7-29.

49. Kim, Y.H. Phenomenological Meaning of Lotus Flower Pattern Symbolism. Korea Sci. ART Forum 2013, 12, 25. [CrossRef]

50. Jang, M.; Hong, J. The study of Wedding Dress by Applying the Pattern of Traditional Wedding Dress-Focused Lotus flower, Arabesque, Peony Patterns. J. Korean Soc. Fash. Beauty 2008, 6, 97-103. 